\title{
The sensory match effect in recognition memory: Perceptual fluency or episodic trace?
}

\author{
JOAN GAY SNODGRASS \\ New York University, New York, New York \\ ELLIOT HIRSHMAN \\ University of North Carolina, Chapel Hill, North Carolina \\ and \\ JIN FAN \\ New York University, New York, New York
}

\begin{abstract}
The sensory match effect in recognition memory refers to the finding that recognition is better when the sensory form in which an item is tested is the same as that in which it was studied. This paper examines the basis for the sensory match effect by manipulating whether a studied fragmented picture is tested with the same or a complementary set of fragments in a recognition memory test (Experiment 1) and in a fragment-identification test (Experiment 2). Assuming that fragment identification is a direct measure of perceptual fluency, we expected identical patterns of results across the two tests if perceptual fluency accounted for the sensory match effect in recognition memory. Instead, recognition memory showed a robust overall sensory match effect (the same fragmented image was recognized better than the complementary image), whereas fragment identification showed no overall sensory match effect (the same fragmented image was identified no better than the complementary fragmented image). Experiments 3 and 4 combined the two responses and showed that the basis for the sensory match effect in recognition memory was a subject's ability to recognize the matching fragments in the absence of conceptual information (when the test stimulus could not be identified), supporting the idea that the episodic trace of the sensory code is responsible for the sensory match effect in recognition memory. Experiment 5 demonstrated that subjects are able to use this sensory code as the sole basis for recognition memory.
\end{abstract}

Dual-process models of recognition memory (Atkinson \& Juola, 1973; Jacoby \& Dallas, 1981; Mandler, 1980) posit two bases for recognition memory. One process is a rapid familiarity judgment that is often assumed to rely on perceptual fluency (Jacoby \& Dallas, 1981; Johnston, Hawley, \& Elliott, 1991). The second process is a slower recall-like search (Atkinson \& Juola, 1974; Humphreys \& Bain, 1983; Mandler, 1980).

The purpose of the present study was to examine the role of perceptual fluency, a central component of many dualprocess models, in accounting for the sensory match effect in recognition memory. Perceptual fluency is the increase in ease or speed of perception conferred on an item by its prior presentation. Jacoby and Dallas (1981) proposed that

This research was supported by Research Grants AFOSR 89-0442 and F49620-92-J-0119 from the U.S. Air Force Office of Scientific Research to J.G.S. We thank Michelle Bahk for help with Experiment 1, Kevin Willenson for help with Experiment 2, Susanna Tsivkin for help with Experiment 3, and Paul Cummings for help with Experiment 5. E.H. was supported by Research Grant SBR-9420248 from the National Science Foundation during the preparation of this report. Correspondence concerning this article should be addressed to J. G. Snodgrass, Dept. of Psychology, New York University, 6 Washington Place, Room 857, New York, NY 10003 (e-mail: gay@xp.psych.nyu.edu). one basis on which subjects could make a recognition memory decision was relative perceptual fluency, or the degree to which a previously experienced item can be more readily perceived than a new item. They supported this position by showing that certain variables, such as number and spacing of repetitions, had equivalent effects on both recognition memory and perceptual identification. Perceptual fluency is assumed to be useful in recognition memory because it indicates whether an item was previously presented, with previously presented items being more fluent. One of the central predictions of any model relying on perceptual fluency is that recognition memory performance will improve when the sensory characteristics of study and test stimuli are more similar. Matching sensory characteristics should enhance perceptual fluency (Richardson-Klavehn \& Bjork, 1988) and should show parallel effects on recognition memory.

The empirical evidence on this prediction is mixed. While several studies have demonstrated that changes in sensory characteristics between study and test have no effect on recognition memory, other studies have demonstrated that sensory matching improves recognition memory. ${ }^{1}$ For example, Snodgrass and Hirshman (1994) manipulated the degree of match between the level of fragmentation presented at study and test in recognition 
memory, speeded naming, fragment identification, and speeded fragment identification. They found that matching fragment levels improved performance on all tasks, demonstrating an association between recognition memory and several tasks measuring perceptual fluency.

While Snodgrass and Hirshman's (1994) results are consistent with the notion that perceptual fluency affects recognition memory, several recent studies (Biederman \& Cooper, 1991a, 1992; Cooper \& Schacter, 1992; Cooper, Schacter, Ballesteros, \& Moore, 1992; Cooper, Schacter, \& Moore, 1991; Schacter \& Cooper, 1993) qualify this conclusion. These studies demonstrate that sensory matching affects recognition memory even when it does not affect implicit memory tests hypothesized to index perceptual fluency. For example, Biederman and Cooper (1991a) showed that changes in spatial position or left-right orientation had no effect on priming in speeded picture naming even though subjects showed the ability to discriminate between old and new positions and orientations. In another study, Biederman and Cooper (1992) showed that moderate changes in object size between study and test had no effect on priming in speeded picture naming, whereas they had substantial effects on both recognition memory accuracy and recognition memory RT. Thus, sensory matching effects in recognition memory do not necessarily implicate perceptual fluency. As suggested by Cooper and her colleagues (Cooper \& Schacter, 1992; Cooper et al., 1992; Cooper et al., 1991; Schacter \& Cooper, 1993), they may reflect the storage of sensory features in episodic memory traces and the concomitant reactivation of those traces when matching sensory features are presented at test. We refer to this view hereafter as the episodic trace hypothesis. A critical difference between the episodic trace and perceptual fluency hypotheses concerns the locus of the sensory match effect. Under the episodic trace hypothesis, sensory match effects arise from a memory system, putatively the hippocampus and its related structures (Squire, 1992), which also represents other declarative information (e.g., semantic elaborations, general contextual information). In contrast, the fluency hypothesis claims that enhancements in the operations of perceptual systems (Tulving \& Schacter, 1990) produce the sensory match effect and influence recognition memory more generally.

Our purpose here was to examine the sensory matching effects reported by Snodgrass and Hirshman (1994), focusing on whether they represented effects of perceptual fluency. We did this by manipulating whether the sensory characteristics of picture fragments presented at study and test matched. We then compared the effects of sensory matching in recognition memory with those in fragment identification, an implicit memory test assumed to index perceptual fluency (Hashtroudi, Ferguson, Rappold, \& Chrosniak, 1988; Hirshman, Snodgrass, Mindes, \& Feenan, 1990; Roediger \& Blaxton, 1987; Roediger, Weldon, Stadler, \& Riegler, 1992; Weldon \& Roediger, 1987). Demonstrating associations between the sensory match effects found in recognition memory and fragment identification would be consistent with a perceptual flu- ency hypothesis. Demonstrating dissociations, on the other hand, suggests that perceptual fluency is not a sufficient explanation of the sensory matching effects in recognition memory reported by Snodgrass and Hirshman (1994) and others.

In Experiment 1, the effect of sensory matching in recognition memory was examined in an attempt to replicate Snodgrass and Hirshman's (1994) findings. During study, subjects attempted to identify fragmented pictures. During test, the subjects were given old and new fragmented pictures and asked to decide whether they were old (a version of the picture had been presented during the study phase) or new (no version of the picture had been presented during the study phase). Test pictures were either old or new, and the old test pictures were either at the same level of fragmentation as at study or more fragmented, and they contained either exactly the same fragments as at study (matching fragments) or the complementary set (different fragments).

\section{STIMULUS GENERATION METHOD}

It was necessary to devise a scheme so that (1) study stimuli were moderately fragmented and so could be identified at least $50 \%$ of the time; (2) test stimuli for fragment identification were sufficiently fragmented so that ceiling effects could be avoided; and (3) study items could be conveniently split into two halves to form the matching and complementary test fragments. In order to accomplish these goals, the pictures were fragmented in terms of percentage of fragments shown rather than in terms of level of fragmentation as had been done in previous research. Pictures were fragmented by identifying, within the $256 \times 256$ pixel square occupied by each picture, the subset of $16 \times 16$ pixel blocks that contained black pixels. Then the target percentage of informative blocks was randomly selected for inclusion in the image. We used pictures at three levels of completeness as study stimuli: a $40 \%$ fragment and the two randomly selected halves of the $40 \%$ fragment, which each contained $20 \%$ of the fragments. These will be referred to as the $20 \% \mathrm{~A}$ and $20 \% \mathrm{~B}$ fragments.

We used pictures at four levels of completeness as test stimuli: $40 \%$ fragments (i.e., the stimulus that matched the $40 \%$ study stimulus), $20 \% \mathrm{~A}$ and $20 \% \mathrm{~B}$ fragments (which either matched or were complementary to one of the two study stimuli), and $10 \% \mathrm{~A}$ fragments (a stimulus containing a randomly selected half of the fragments of the $20 \%$ A stimulus). Any subject saw a particular item in only one of the possible study/test combinations.

The stimuli were 96 pictures of objects and animals selected from Snodgrass and Vanderwart (1980) and prepared for presentation on the Apple Macintosh microcomputer. Each picture had been prepared in all four fragmentation levels $(40 \%, 20 \% \mathrm{~A}, 20 \% \mathrm{~B}$, and $10 \% \mathrm{~A}$ ) by a computer procedure that randomly selected $40 \%$ of the fragments, displayed them, then randomly selected two halves of the $40 \%$ stimulus to produce the $20 \% \mathrm{~A}$ and $20 \% \mathrm{~B}$ fragments, displayed the two halves side by side, and finally randomly selected half of the fragments from the $20 \% \mathrm{~A}$ stimulus and displayed the $10 \% \mathrm{~A}$ stimulus. An experimenter monitored this procedure and repeated it as many times as necessary for each picture until the fragment series was acceptable. The major criterion for acceptability was that the $20 \% \mathrm{~A}$ and $20 \% \mathrm{~B}$ fragments appear equally identifiable, although the experimenter also rejected series in which either the $40 \%$ fragment was too easy or the $10 \%$ fragment was impossibly difficult.

To simplify the design, only the $20 \% \mathrm{~A}$ fragment was used as the study stimulus in Experiments 1-3, so that the test stimulus that matched the study stimulus was always the $20 \% \mathrm{~A}$ fragment and the 
test stimulus that was complementary was always the $20 \% \mathrm{~B}$ fragment. In Experiment 4, although no apparent differences were observed between performance on the two versions of the $20 \%$ fragment in neutral testing conditions, both versions were used as both study and test items so that complete counterbalancing could be accomplished.

Figure 1 shows examples of the stimuli at each of the four levels. Of the 96 pictures, 90 were used as experimental items and 6 served as practice items.

\section{EXPERIMENT 1}

\section{Method}

Subjects and Design. The subjects were 36 students in an introductory psychology course, who volunteered in fulfillment of a course requirement. In Experiment 1, only three fragmentation levels-20\%A, $20 \% \mathrm{~B}$, and $40 \%$-were used. During the study phase, two levels of fragmented images-20\%A and $40 \%$-were presented. There were 30 study items at each of the two levels. During the test phase, three levels of fragmented images- $20 \% \mathrm{~A}, 20 \% \mathrm{~B}$, and $40 \%$-were presented. There were 30 test items at each of the three levels, 10 that had been studied at $20 \% \mathrm{~A}, 10$ that had been studied at $40 \%$, and 10 that were new. The total number of old items was 60 and the total number of new items was 30 , so the ratio of old-to-new items was $2: 1$.

The experiment thus had a 3 (study level: $20 \% \mathrm{~A}, 40 \%$, and new) $\times 3$ (test level: $20 \% \mathrm{~A}, 20 \% \mathrm{~B}$, and $40 \%$ ) design. The 90 experimental items were rotated across the nine experimental conditions to produce nine counterbalancing conditions. Equal numbers of subjects were assigned to each counterbalancing.

Apparatus and Procedure. The subjects were tested individually on Apple Macintosh Plus microcomputers. Prior to beginning the experiment, they were told that they would be asked to identify pictures that would appear on the screen of the computer as fragmented images. The subjects then signed a consent form that assured them of anonymity and informed them that they had the right to withdraw from the experiment at any time and to ask that their responses not be used.

For the study phase, the subjects were told that the purpose of the experiment was to find out how people identified pictures and that they would be shown pictures of common objects and animals, some of which would be more complete than others. Each picture would be shown for $2 \mathrm{sec}$, and at the end of each presentation the picture
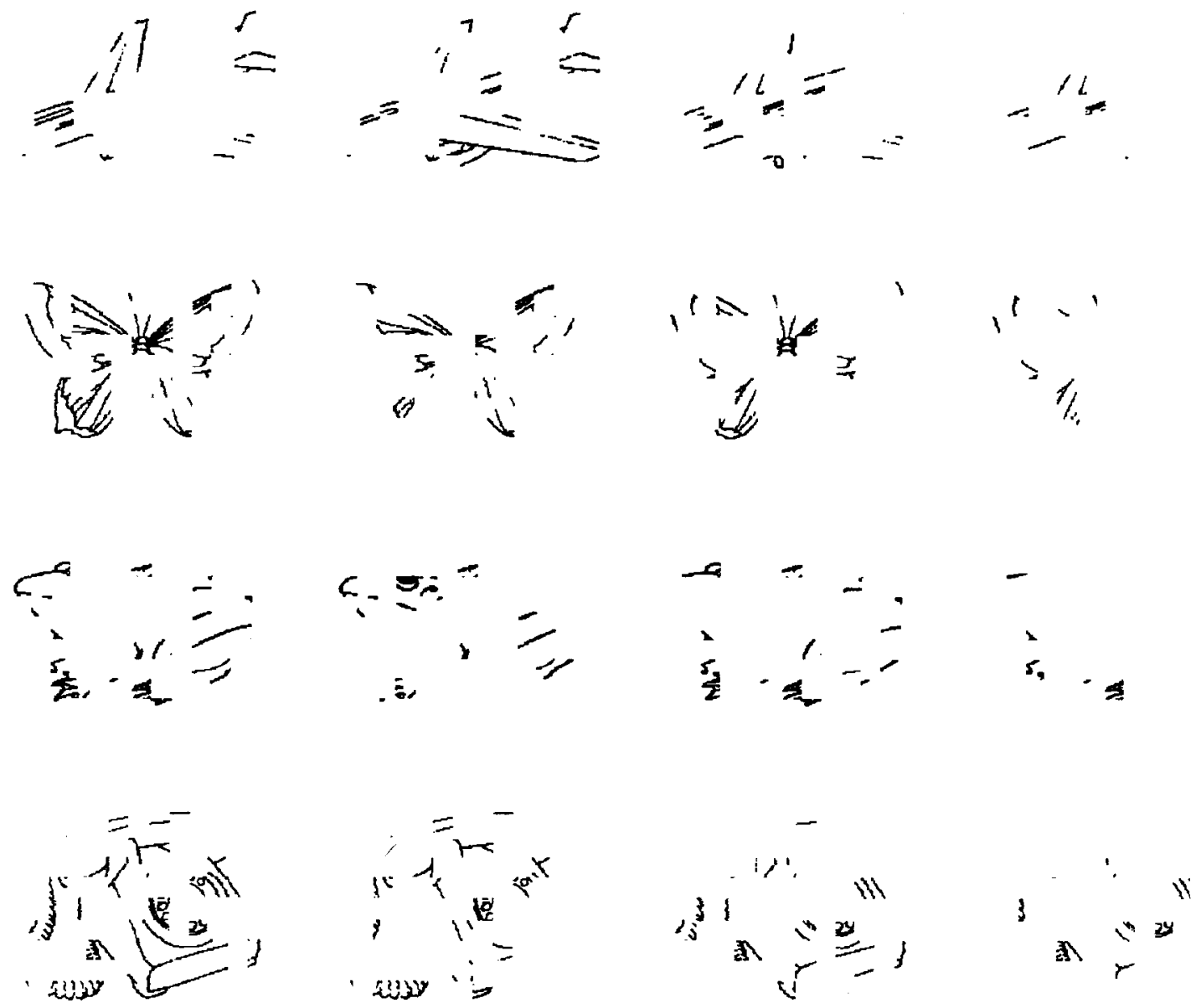

Figure 1. Examples of pictures fragmented at each of the possible study or test levels. The $20 \% \mathrm{~A}$ and $20 \% \mathrm{~B}$ fragments were created by randomly selecting half of the elements from the $40 \%$ fragment, and the $10 \% \mathrm{~A}$ fragment was created by randomly selecting half of the elements from the $20 \% \mathrm{~A}$ fragment. 
would be erased and the subjects would be asked to name the picture. They were told to type their best guess of the picture's name and then to press return; if they had no idea what the picture was, they were to type "blank," since the program would not go on until they had typed something. They were told that they needed to type only the first four letters of the picture's name to be correct, and that some pictures might have more than one correct name.

To motivate them to do well, the subjects were told that they would earn 5 points for each picture they identified correctly in this phase of the experiment, that they would be informed of their running total of points after each response, and that the subject who earned the most points would win $\$ 25$.

The study sequence consisted of 64 trials; the first 4 were practice trials, distributed equally across the two fragmentation conditions, and were not scored. The remaining 60 were the experimental trials, 30 at the $20 \% \mathrm{~A}$ level and 30 at the $40 \%$ level. Pictures at the two levels were randomly intermixed. After each fragmented picture was presented for $2 \mathrm{sec}$ and then erased, the subject was asked to type the name of the picture. Subjects were forced to type something or the program would not continue. The subjects were given feedback at the end of each trial. They were told whether they were correct or incorrect, and when they were incorrect, they were shown the correct name of the picture. Correctness was determined with reference to a list of possible names for each picture. These names included common misspellings, abbreviations (e.g., tv for television and bike for bicycle), and synonyms (e.g., slacks for pants). They earned 5 points for each correct response; after each response, they were shown the running total number of points they had earned. There was a 1 -sec intertrial interval.

After the study sequence, the subjects received a distractor task consisting of five simple addition problems lasting about $1 \mathrm{~min}$. The final phase was the recognition memory test. The subjects were told that, in this phase of the experiment, we would test their memory of the pictures from the experiment. The pictures would be shown to them one at a time. Some of them would be old-that is, they had been shown in the first part of the experiment--and some of them would be new-that is, they had not been shown before. They were also told that some of the old pictures would be exactly the same as they had been in the first part, some of the old pictures would be less complete, and some would be more complete. They were instructed to consider a picture as old if they had seen the picture before in any version.

The subjects were instructed to hit the bottom right-hand key (the ?/ key) if they thought the picture was old, and to hit the bottom left-hand key (the $z Z$ key) if they thought the picture was new. They were also told to respond with their first reactions, and not to agonize over their decisions. They were told to make their decisions as quickly as possible, but also to make as few errors as possible.

To reinforce that instruction, the subjects were told that they would receive 5 points for each correct response made within $1,000 \mathrm{msec}$, but that they would lose 5 points for each error. A correct response that took longer than $1,000 \mathrm{msec}$ would earn 0 points. The subjects received feedback with regard to the number of points won or lost after each response. They were also informed that the points from this phase of the experiment would be added to the points they had earned during the first part of the experiment and were reminded that the subject who earned the most points would win $\$ 25$.

During the recognition memory test, the subjects were shown 90 test pictures, 30 at the $20 \% \mathrm{~A}$ level, 30 at the $20 \% \mathrm{~B}$ level, and 30 at the $40 \%$ level. One third of the pictures at each test level had been seen at the $20 \% \mathrm{~A}$ level at study, one third had been seen at the $40 \%$ level at study, and one third were new. The words OLD and NEw were shown at the bottom of the screen on the right and left, respectively, to remind the subjects which key went with which response. A trial began with a 1 -sec exposure of the warning message "get ready," followed by a $0.5-\mathrm{sec}$ blank interval. The test picture was displayed until the subject responded, at which point the picture was erased and feedback in the form of the number of points won or lost was dis- played for $2 \mathrm{sec}$, followed by a 0.5 -sec blank interval. Both study and test sequences were randomized separately for each subject. Both response correctness and response time (to the nearest $16 \mathrm{msec}$ ) were recorded. Six practice trials preceded the 90 test trials.

At the end of the experiment, the subjects were thanked for their participation, informed of the total number of points earned, and given a written debriefing statement.

\section{Results and Discussion}

During the study phase, subjects identified more stimuli presented at the $40 \%$ level than at the $20 \%$ level $(87 \%$ and $53 \%$, respectively).

Because experiments across the series often replicate comparable conditions, we will present the results of more than one experiment in each table when similarities in their designs permit. Table 1 shows proportion of recognition responses (hits and false alarms) and $d^{\prime}$ values for each combination of study and test conditions in Experiment 1 . Several effects are evident in the table. First, replicating Snodgrass and Hirshman (1994), matching fragments $(20 \% \mathrm{~A} / 20 \% \mathrm{~A})$ had higher hit rates than nonmatching fragments $(20 \% \mathrm{~A} / 20 \% \mathrm{~B}-.80$ vs. .69). Second, the $40 \%$ study level produced higher hit rates than the $20 \%$ A study level (.82 vs. .76). Third, the $40 \%$ test level produced higher hit rates than either the $20 \% \mathrm{~A}$ or the $20 \% \mathrm{~B}$ test level (.85 vs. .78 and .74$)$. False-alarm rates for new pictures were also lower for the more complete $40 \%$ level than for the less complete $20 \% \mathrm{~A}$ and $20 \% \mathrm{~B}$ levels (.21 vs. .34 and .36$)$.

Before computing $d^{\prime}$, hit and false-alarm rates were adjusted according to the procedure described in Snodgrass and Corwin (1988) in order to avoid hit rates of 1 and falsealarm rates of 0 . The $d^{\prime}$ values were computed by pairing hit and false-alarm rates by test condition. The $d^{\prime}$ values show effects similar to those of the hit rates. The more complete $(40 \%)$ study stimulus was recognized better than the less complete $(20 \% \mathrm{~A})$ study stimulus except for the $20 \% \mathrm{~A}$ test condition, where the advantage of sensory matching outweighed that of a more complete study stimulus. In addition, the more complete ( $40 \%$ ) test stimulus conferred an advantage in recognition across the board. Most importantly, a sensory match effect occurred: Performance in the $20 \% \mathrm{~A}$ study condition was better for matching than for complementary test fragments $\left(d^{\prime}\right.$ values of 1.23 vs. 0.88$)$.

Table 1

Recognition Memory Performance in Experiments 1 and 3

\begin{tabular}{|c|c|c|c|c|c|}
\hline \multirow[b]{3}{*}{ Test Level } & \multicolumn{3}{|c|}{ Study Level } & \multirow{2}{*}{\multicolumn{2}{|c|}{$d^{\prime}$ Values }} \\
\hline & \multirow{2}{*}{$\begin{array}{c}20 \% \mathrm{~A} \\
\text { (Hit) }\end{array}$} & \multirow{2}{*}{$\begin{array}{l}40 \% \\
\text { (Hit) }\end{array}$} & \multirow{2}{*}{$\begin{array}{l}\mathrm{New} \\
(\mathrm{FA})^{*}\end{array}$} & & \\
\hline & & & & $20 \% \mathrm{~A}$ & $40 \%$ \\
\hline \multicolumn{6}{|c|}{ Experiment 1} \\
\hline $20 \% \mathrm{~A}$ & 0.80 & 0.76 & 0.34 & 1.23 & 1.10 \\
\hline $20 \% \mathrm{~B}$ & 0.69 & 0.79 & 0.36 & 0.88 & 1.17 \\
\hline $40 \%$ & 0.80 & 0.91 & 0.21 & 1.67 & 2.08 \\
\hline \multicolumn{6}{|c|}{ Experiment 3} \\
\hline $20 \% \mathrm{~A}$ & 0.86 & 0.84 & 0.17 & 1.97 & 1.91 \\
\hline $20 \% \mathrm{~B}$ & 0.76 & 0.83 & 0.18 & 1.62 & 1.82 \\
\hline $40 \%$ & 0.85 & 0.96 & 0.07 & 2.41 & 2.85 \\
\hline
\end{tabular}

${ }^{*} \mathrm{FA}=$ false alarm. 
The results of a 2 (study level) $\times 3$ (test level) analysis of variance (ANOVA) on $d^{\prime}$ showed these effects to be reliable. The more complete study level produced better performance $\left[F(1,35)=15.57, M S_{\mathrm{e}}=.127, p<.001\right]$, the more complete test level produced better performance $\left[F(2,70)=28.55, M S_{\mathrm{e}}=.527, p<.001\right]$, and the study and test levels interacted $\left[F(2,70)=8.47, M S_{\mathrm{e}}=.174\right.$, $p<.001]$. A planned contrast between the matching $(20 \% \mathrm{~A} / 20 \% \mathrm{~A})$ and complementary $(20 \% \mathrm{~A} / 20 \% \mathrm{~B})$ conditions showed that the matching condition was significantly better $(p=.02)$. Thus, the $d^{\prime}$ measure showed a clear advantage for matching over mismatching fragments.

The recognition memory hit reaction times (RTs) show the same pattern as the hit rates and, for simplicity of exposition, will not be presented here. However, a planned contrast between the matching $(20 \% \mathrm{~A} / 20 \% \mathrm{~A})$ and mismatching $(20 \% \mathrm{~A} / 20 \% \mathrm{~B})$ hit RTs revealed that the matching RTs were significantly faster (905 vs. $959 \mathrm{msec} ; p=$ .05 ).

The advantages of more complete study and test items probably derive from the influence of completeness on identification. This can be understood by considering the effects of identification on the lower level sensory and higher level conceptual components of information stored at study and retrieved during test. When an item is identified at study, conceptual and sensory information are available simultaneously, allowing for their integration. When an item is not identified and its name is presented to subjects, sensory information may remain fragmented and/or it may not be integrated with conceptual information. Thus, identification at study increases the probability of storing important memorial information, facilitating later recognition memory. Similarly, when an item is not identified at test, conceptual and sensory information is available only incompletely, reducing the probability of retrieving similar information from memory.

In Experiment 1, the subjects did not attempt to identify items before making their recognition memory judgments, so we have no way of evaluating whether successful identification of the fragment at test led to better recognition memory performance (we pursued this issue in Experiment 3 below). However, we do have information on whether each item was successfully identified at study. Accordingly, we analyzed recognition memory hits by whether the items were correctly identified at study for the matching $(20 \% \mathrm{~A} / 20 \% \mathrm{~A})$ and mismatching $(20 \% \mathrm{~A} /$ $20 \% \mathrm{~B}$ ) fragments. This analysis is presented for hit rates rather than for $d^{\prime}$ values because new items cannot be classified by whether or not they were identified at study, so there is no way of partitioning the false-alarm rate by this variable.

This conditionalized analysis also allows us to evaluate whether the sensory match effect is approximately the same for identified and unidentified study items. If we assume that identification at study integrates sensory and conceptual information, then finding approximately equal sensory match effects for identified and unidentified study items suggests that such integration does not contribute greatly to the match effect. Similarly, identi- fication of a fragmented study item will be accompanied by the perceptual closure process discussed by Snodgrass and Feenan (1990). Finding approximately equal sensory match effects for identified and unidentified study items also suggests that perceptual closure does not contribute greatly to the effect.

Table 2 shows hit rates for both identified and unidentified $20 \%$ A study items tested at either $20 \% \mathrm{~A}$ or $20 \% \mathrm{~B}$. These conditionalized recognition scores show two important effects. First, items identified at study are more likely to be recognized as old at test than are items not identified at study. This "identification advantage" is consistent with the idea that differences in identifiability mediate the effect of study level presented above. Second, both identified and nonidentified study items show a matching advantage. In fact, the match advantage is numerically larger for unidentified items than for identified items (0.15 vs. 0.09$)$.

A $2 \times 2$ ANOVA on hit rates for the $20 \%$ study and test conditions showed that identified items were significantly better recognized than unidentified items $\left[F(1,35)=12.85, M S_{\mathrm{e}}=.043, p<.001\right]$, that matching fragments were significantly better recognized than nonmatching fragments $\left[F(1,35)=11.51, M S_{\mathrm{e}}=.045, p=\right.$ $.002]$, but that there was no significant interaction $(F<1)$. Unfortunately, the lack of a significant interaction cannot be taken to prove that the matching advantage for identified and unidentified study items was equal, particularly as the baseline for identified items is higher than that for unidentified items. As we have argued elsewhere, the same absolute difference in performance may be more difficult to accomplish with a higher than with a lower baseline (Snodgrass, 1989). However, as shown in Table 2, we replicated this pattern of results in Experiment 3 with the match advantage still statistically equivalent but in the opposite direction. And the important point here is that sensory match effects are positive across both identified and unidentified study items. As we shall see, a similar analysis on fragment-identification performance produces a very different pattern of results.

As mentioned previously, the finding of positive sensory match effects for both identified and unidentified items has important implications for our understanding of the sensory match effect. It suggests that processes correlated with identification, such as the integration of sen-

Table 2

Recognition Memory Performance (Hit Rates) Conditionalized on Correct Identification at Study for Experiments 1 and 3

\begin{tabular}{|c|c|c|c|}
\hline & \multicolumn{2}{|c|}{ Study Level/Test Level } & \multirow{2}{*}{$\begin{array}{c}\text { Match } \\
\text { Advantage }\end{array}$} \\
\hline & $20 \% \mathrm{~A} / 20 \% A$ & $\% \mathrm{~A} / 20 \% \mathrm{~B}$ & \\
\hline \multicolumn{4}{|c|}{ Experiment 1} \\
\hline Identified at study & 0.84 & 0.75 & 0.09 \\
\hline Not identified at study & 0.75 & 0.60 & 0.15 \\
\hline Identification advantage & 0.09 & 0.15 & \\
\hline \multicolumn{4}{|c|}{ Experiment 3} \\
\hline Identified at study & 0.96 & 0.80 & 0.16 \\
\hline Not identified at study & 0.78 & 0.71 & 0.07 \\
\hline Identification advantage & 0.18 & 0.09 & \\
\hline
\end{tabular}


sory and conceptual information and enhanced perceptual closure, are not critical to the sensory match effect. This seems to present an immediate problem for a perceptual fluency account since the processes correlated with identification - the integration of sensory and conceptual information and enhanced perceptual closure-also increase perceptual fluency. In contrast, the episodic trace view provides a straight-forward account of this result. Sensory information can be stored with conceptual and contextual information in a declarative memory system. This can occur whether or not an item is identified. Thus, even when subjects fail to identify a target at study, its sensory characteristics can be a component of the memory trace, facilitating later memory and resulting in the same match advantage for both identified and unidentified test items.

The most important results of Experiment 1 are that sensory matching provides a recognition memory advantage and that this advantage occurs for both identified and unidentified items. Above, we argued that this sensory matching advantage was unlikely to be due to perceptual fluency. Note, however, that the faster recognition memory hit RTs reported for matching items above are consistent with the fluency hypothesis. On the other hand, such differences might also be produced by a speeded decision process for the more easily recognized stimulus class. Given this ambiguity and the preceding evidence against the fluency hypothesis, Experiment 2 was designed to investigate the fluency hypothesis more directly by determining whether matching fragments produced greater identification at test. If we equate perceptual fluency with increased identifiability, then the perceptual fluency hypothesis predicts that matching fragments at test should improve perceptual identification - that is, a sensory match advantage should be observed in fragment identification in the same way as it was in recognition memory.

Experiment 2 was identical to Experiment 1 in its study phase. The major difference was in the test phase, in which subjects were asked to identify fragmented pictures rather than to make judgments about their prior occurrence. Some of the test pictures were old and some were new, and old test pictures were either at the same level of fragmentation as at study or more fragmented, and they either contained exactly the same fragments as at study (matching fragments) or the complementary set (different fragments).

\section{EXPERIMENT 2}

\footnotetext{
Method

Subjects and Design. The subjects were 27 students in an introductory psychology course, who volunteered as part of a course requirement. During the study phase, two levels of fragmented images $-20 \% \mathrm{~A}$ and $40 \%$-were presented. During the test phase, three levels-20\%A, $20 \% \mathrm{~B}$, and $10 \% \mathrm{~A}$-were presented. Equal numbers of test items at each of the two study levels were presented along with some new items so that priming effectiveness could be evaluated. Because there were two study conditions and only one baseline (new) condition, the ratio of old to new items was $2: 1$.
}

The design of Experiment 2 was identical to that of Experiment 1 , with the exception that the $40 \%$ test condition was replaced by the $10 \% \mathrm{~A}$ test condition in order to provide more opportunities for errors. The experiment thus had a 3 (study level: $20 \% \mathrm{~A}, 40 \%$, and new) $\times 3$ (test level: $20 \% \mathrm{~A}, 20 \% \mathrm{~B}$, and $10 \% \mathrm{~A}$ ) design. The $90 \mathrm{ex}-$ perimental items were rotated across the nine experimental conditions to produce nine counterbalancing conditions. Equal numbers of subjects were assigned to each counterbalancing.

Apparatus and Procedure. The subjects were tested individually on Apple Macintosh Plus microcomputers. They were given exactly the same instructions for the study phase as the subjects in Experiment 1 had been. They were also given the opportunity to win a prize of $\$ 25$ by earning points for each picture they identified correctly during the study phase. During the study phase, the subjects received 60 study trials, 30 at the $20 \% \mathrm{~A}$ level and 30 at the $40 \%$ level. Four practice trials, 2 at each study level, preceded these study trials.

After the study phase, the subjects received a computeradministered distractor task. During the distractor task, the subjects were presented with 10 pairs of abstract visual patterns, randomly selected from a larger set, and asked to decide whether the pattern pairs were the same or different and to respond by pressing one of two buttons. They were informed whether each response was correct or incorrect. At the end of the distractor task, each subject was informed of his or her percentage of correct responses. The distractor task lasted about $1 \mathrm{~min}$.

The final phase was the fragment-identification test. The subjects were told that in this phase of the experiment they would see more fragmented pictures, and that they would be asked to identify each picture by typing its name on the keyboard. As before, they were told that they could type only the first four letters for long names, that some pictures had more than one name, and that they had to type something or the program would not go on. In addition, they were informed that, as in the first phase of the experiment, they would receive 5 points for each picture they named correctly.

During the fragment-identification test, the subjects were shown 90 test pictures, 30 at the $20 \% \mathrm{~A}$ level, 30 at the $20 \% \mathrm{~B}$ level, and 30 at the $10 \% \mathrm{~A}$ level. One third of the pictures at each test level had been seen at the $20 \% \mathrm{~A}$ level at study, one third had been seen at the $40 \%$ level, and one third were new. The subjects were given cor$\mathrm{rect} /$ incorrect feedback to each response, but were told the name of the picture only when it was incorrect. The criterion for correctness was the same as that used in the study phase. The subjects were awarded 5 points for each correct response, and were shown the running total number of points after each response. There was a $1-\mathrm{sec}$ intertrial interval. In addition to on-line scoring for correctness, responses during the study and test phases were stored and examined after the experiment, and any response that could plausibly be interpreted as indicating correct identification was scored as correct. At the end of each experiment, the subjects were thanked and given a written debriefing statement.

\section{Results and Discussion}

During the study phase, the subjects identified more stimuli presented at the $40 \%$ level than they did at the $20 \%$ level ( $81 \%$ and $47 \%$, respectively).

Table 3 shows the proportion of items identified under each of the nine study/test conditions, along with the priming scores. The $40 \%$ study level produced greater priming than did the $20 \%$ A priming level, the two $20 \%$ test levels produced equivalent performance, and the $10 \%$ test level was identified at a much lower level. Most importantly, in contrast to recognition memory there was no sensory match effect in fragment identification. The $20 \% \mathrm{~A}$ fragment tested with itself produced $68 \%$ identi- 
fications; the $20 \% \mathrm{~A}$ fragment tested with its complement $(20 \% \mathrm{~B})$ also produced $68 \%$ identifications.

The priming scores (studied minus new) also show that the $40 \%$ study level was a more effective prime than the $20 \%$ study level, but that there was no advantage of matching study and test fragments. Priming for the $20 \% \mathrm{~A} / 20 \% \mathrm{~A}$ condition of $16 \%$ is virtually identical to priming for the $20 \% \mathrm{~A} / 20 \% \mathrm{~B}$ condition of $17 \%$. In addition, converting the identification scores to priming scores produces comparable performance for the easy $(20 \%)$ and difficult $(10 \%)$ test levels, producing a remarkably similar pattern of results across all three test levels.

The results of a 2 (study level) $\times 3$ (test level) withinsubjects ANOVA on the priming scores showed that only the main effect of study level was significant $[F(1,26)=$ 13.07, $\left.M S_{\mathrm{e}}=.024, p=.0013\right]$. Neither the test level nor the interaction of the study and test levels was significant (both $F \mathrm{~s}<1$ ).

The results of Experiment 2 may be summarized as follows: First, the $40 \%$ study stimulus consistently primed better than the $20 \%$ priming stimulus. This was true for both raw scores and priming (difference) scores. Although this result has implications for the perceptual closure hypothesis proposed by Snodgrass and Feenan (1990), it is peripheral to our present concerns and so we defer its discussion until later in the paper.

Second, and most importantly, there was no advantage of matching over complementary fragments at test when either raw or priming scores were considered. Although these results differ from others reported in the literature (Hashtroudi et al., 1988; Roediger \& Blaxton, 1987; Roediger et al., 1992; Snodgrass \& Hirshman, 1994; Srinivas, 1993; Weldon \& Roediger, 1987), they are consistent with those of Biederman and Cooper (1991b), who reported a similar lack of specificity of priming, but only for fragmented pictures whose geons (object parts) were still retrievable. Presumably, the degree to which priming is sensitive to sensory match effects is determined to a large degree by the type and magnitude of such effects. Changes in the form of a representation from words to pictures (Weldon \& Roediger, 1987), or even in the degree of fragmentation from moderately fragmented to complete (Snodgrass \& Hirshman, 1994), are more profound in degree than Biederman and Cooper's (1991b) and our fairly subtle manipulation of keeping the degree

Table 3

Fragment Identification Performance in Experiments 2 and 3

\begin{tabular}{lcccccc}
\hline & \multicolumn{3}{c}{ Study Level (Proportion Identified) } & \multicolumn{2}{c}{ Priming } \\
\cline { 2 - 4 } \cline { 5 - 6 } Test Level & $20 \% \mathrm{~A}$ & $40 \%$ & New & & $20 \% \mathrm{~A}$ & $40 \%$ \\
\hline \multicolumn{5}{c}{ Experiment 2} \\
$20 \% \mathrm{~A}$ & 0.68 & 0.78 & 0.52 & 0.16 & 0.26 \\
$20 \% \mathrm{~B}$ & 0.68 & 0.76 & 0.51 & 0.17 & 0.25 \\
$10 \% \mathrm{~A}$ & 0.27 & 0.35 & 0.12 & 0.14 & 0.23 \\
\multicolumn{7}{c}{ Experiment 3} \\
$20 \% \mathrm{~A}$ & 0.75 & 0.79 & 0.63 & 0.13 & 0.17 \\
$20 \% \mathrm{~B}$ & 0.72 & 0.83 & 0.58 & 0.13 & 0.24 \\
$40 \%$ & 0.94 & 0.97 & 0.90 & 0.04 & 0.07 \\
\hline
\end{tabular}

of fragmentation of a picture the same and varying only which elements are present in the image. (See analyses presented below for further insights into the current failure to produce sensory match effects in identification.)

In summary, there were no sensory match effects in Experiment 2 in fragment identification. This contrasts with the results of Experiment 1, which showed robust sensory match effects in recognition memory. The combined results of Experiments 1 and 2 suggest that perceptual fluency does not provide a sufficient explanation of the sensory match effect in recognition memory. The match effect occurred in recognition memory but not in perceptual identification, a task hypothesized to index perceptual fluency.

Recall that for recognition memory, the sensory match effect occured for fragments identified during study and for fragments not identified during study. We wondered what effect successful identification during study would have on the sensory match effect in identification, particularly since Snodgrass and Feenan (1990) found a strong relationship between successful identification at study (an index of perceptual closure) and subsequent test identification. Accordingly, we examined test identification scores conditionalized on correct identification at study for the two $20 \%$ study/test conditions.

These conditionalized identification scores, shown in Table 4, exhibit one similarity and one difference between them and those of the conditionalized recognition memory scores of Experiment 1 (see Table 2). First, similar to recognition memory, items identified at study are more likely to be identified at test than are items not identified at study. The magnitude of this effect is numerically larger than it is in recognition memory, as shown in the "Identification advantage" row. Second, we observe, for the first time, an advantage in fragment identification for the matching-fragment condition $(20 \% \mathrm{~A} / 20 \% \mathrm{~A})$ as compared with the complementary-fragment condition $(20 \% \mathrm{~A} / 20 \% \mathrm{~B})$, but this occurs only for items identified at study. Conversely, there is a matching disadvantage for unidentified items; the nonmatching-fragment condition was better than the matching-fragment condition for items incorrectly identified at study. These virtually complementary differences are shown in the "Match Advantage" column. While the matching advantage for identified items is significant by a matched $t$ test $[t(26)=2.18$, $p=.02]$, the matching disadvantage for nonidentified items does not attain the traditional criterion for significance $[t(26)=1.31, p=.10]$. However, as shown in Table 4 , the numerical pattern of means is replicated in Experiment 3 , suggesting that it may be reliable. We believe this matching disadvantage arises because the generation of an erroneous hypothesis at study harms later identification, particularly when the sensory features of the study and test item match (see Bruner \& Potter, 1964, for an analogous effect). Thus, there may be two related factors contributing to the null effect found in Experiment 2: identification successes produce a matching benefit and identification failures produce a matching deficit. ${ }^{2}$ Note that the matching advantage for identified 
Table 4

Fragment Identification Scores Conditionalized on Correct Identification at Study for Experiments 2 and 3

\begin{tabular}{lccc}
\hline & \multicolumn{2}{c}{ Study Level/Test Level } & $\begin{array}{c}\text { Match } \\
\text { Advantage }\end{array}$ \\
\cline { 2 - 3 } & $20 \% \mathrm{~A} / 20 \% \mathrm{~A}$ & $20 \% \mathrm{~A} / 20 \% \mathrm{~B}$ & \\
Identified at study & Experiment 2 & & \\
Not identified at study & 0.93 & 0.84 & 0.09 \\
Identification advantage & 0.47 & 0.56 & -0.09 \\
& 0.46 & 0.28 & \\
Identified at study & Experiment 3 & & \\
Not identified at study & 0.98 & 0.81 & 0.18 \\
Identification advantage & 0.56 & 0.64 & -0.08 \\
\hline
\end{tabular}

study items is similar to that observed in recognition memory, but that the matching disadvantage for unidentified study items is the opposite of that observed in recognition memory.

It is important to rule out item variability as an explanation for the match benefit that emerges when test identification is made conditional on correct identification at study. One might hypothesize that attempting to equate two fragments for identifiability is not possible, and that inevitably one fragment will be easier than another. If the easier fragment is used as a prime, it will more likely be successfully identified at both study and test; conversely, if the more difficult fragment is used as a prime, it will more likely fail to be identified at both study and test. Thus, there will be a spurious correlation between performance at study and test caused by item variability.

We carried out the following analyses to test the itemvariability explanation of the conditionalized results. There are two conditions in which identification of the $20 \% \mathrm{~A}$ and $20 \% \mathrm{~B}$ fragments can be unambiguously compared. The first is when they are presented as new items during test, and the second is when they are presented as test items for a $40 \%$ study prime. We carried out both comparisons. The proportions of subjects identifying each item in each version were compared with a Fisher's $Z$ test for proportions. Some items are missing because no subjects identified either version. For the new items, only 6 of 87 showed a significant $(p<.05)$ deviation from equal performance for the two versions, which is not much different from the 4.35 expected on the basis of chance. For the old items, only 2 of 88 showed a significant $(p<.05)$ deviation from equal performance for the two versions, a number that is less than expected by chance. Accordingly, we conclude that item variability is not a viable explanation for our results. Instead, we conclude that successfully identifying an item during the study episode produces enhanced identification of that same item when its sensory features match at test.

While the conditional analyses reveal substantial and important complications in the results of Experiments 1 and 2, they do not mitigate our conclusions about perceptual fluency and recognition memory. A sensory match effect occurs in recognition memory, but a reverse effect occurs in fragment identification, a task hypothesized to index perceptual fluency, when items are not identified at study. Furthermore, the sensory match effect emerged for items identified at study in fragment identification but did not increase measurably for items identified at study in recognition memory. Given these dissociations, it is unlikely that perceptual fluency is a sufficient explanation of the sensory match effect in recognition memory.

One criticism of this conclusion is that Experiment 2 was conducted as an implicit memory test. In contrast, Experiment 1 was an explicit memory task in which subjects, in order to answer the old/new question, were encouraged to think back to the study episode. It is possible that if subjects are encouraged to think back to the study episode when they attempt to identify a fragmented image, this will produce a sensory match effect in fragment identification as well as in recognition memory. Therefore, we conducted a third experiment, in which subjects were asked to do both tasks during test. First, the subjects were asked to identify the test item, and then they were required to classify it as old or new.

In addition to determining whether the results of Experiment 2 replicate when subjects are given explicit instructions to think back to the study episode, in Experiment 3 we also examined an implication of the episodic trace view. If sensory information is stored in episodic memory traces, there should be sensory match effects in recognition memory even when subjects fail to identify items at test. This can be examined by conditionalizing recognition memory performance on correct and incorrect identification for matching and mismatching test items.

\section{EXPERIMENT 3}

Experiment 3 was exactly the same as Experiment 1 except for the addition of an identification test prior to the recognition test. During the study phase, subjects were shown fragmented pictures to identify and were informed of the name of the picture when they were incorrect. In the test phase, the subjects were given old and new fragmented pictures and were first asked to identify the picture by typing its name. Next, they were asked to decide whether each picture was old (i.e., if a version of the picture had been presented during the study phase) or new (i.e., if no version of the picture had been presented during the study phase).

\section{Method}

Subjects and Design. The subjects were 36 students in an introductory psychology course, who had volunteered in fulfillment of a course requirement. The stimuli and design were identical to those in Experiment 1. There were two dependent variables measured at test: proportion of correct identifications and proportion of correct old/new recognitions.

Apparatus and Procedure. The subjects were tested individually on Apple Macintosh microcomputers. They were given exactly the same instructions for the study phase as had the subjects in Experiment 1 . They were also given the opportunity to win a prize of $\$ 25$ by earning points for each picture they identified during the study phase. During the study phase, the subjects received 60 
study trials, 30 at the $20 \% \mathrm{~A}$ level and 30 at the $40 \%$ level. Four practice trials, two at each study level, preceded these study trials.

After the study sequence, the subjects received a distractor task consisting of five simple addition problems. The distractor task lasted about $1 \mathrm{~min}$. The final phase was the identification/recognition memory test. The subjects were instructed that in this phase of the experiment they would be asked to identify more fragmented pictures. They were also told that after each of their identification responses, they would be asked to decide whether the picture they had just seen was old (shown in the first part of the experiment) or new (not shown before). They were also told that some of the old pictures would be exactly the same as they had been in the first part, that some of the old pictures would be less complete and some would be more complete. They were instructed to consider them as old if they had seen the picture before in any version.

During the identification/recognition memory test, the subjects were shown 90 test pictures, 30 at the $20 \%$ A level, 30 at the $20 \% \mathrm{~B}$ level, and 30 at the $40 \%$ level. One third of the pictures at each test level had been seen at the $20 \% \mathrm{~A}$ level at study, one third had been seen at the $40 \%$ level at study, and one third were new.

On each test trial, the subjects were shown the test picture and prompted with the question, "What do you think it is?" They werc required to type some response or the program would not continue. After they had typed each of their identification responses, they were given correct/incorrect feedback and were informed of the total number of points they had won to that point. They won 5 points for each correct identification. The subjects were not, however, told the identity of the picture if they failed to identify it correctly.

To initiate the recognition memory part of the trial, the words OLD and NEW appeared at the bottom of the screen to the right and left, respectively, as a prompt for the recognition memory response and also to remind the subjects which key went with which response. The subjects were instructed to press the bottom right-hand key (the ?/ key) if they thought the picture was old, and to press the bottom left-hand key (the $\mathrm{zZ}$ key) if they thought the picture was new. They were also told to respond with their first reactions, and not to agonize over their decisions. They were told to make their decisions as quickly as possible, but also to make as few errors as possible.

The subjects won 5 points for each correct recognition response that took less than 1,000 msec to make, won 0 points for a correct recognition response that took more than $1,000 \mathrm{msec}$, and lost 5 points for each recognition error. The feedback for the recognition response was in the form of points won or lost. The identification feedback was displayed for $1 \mathrm{sec}$ and the recognition feedback was displayed for $2 \mathrm{sec}$, followed by a 0.5 -sec blank interval before the next trial began. As in previous experiments, points from this phase of the experiment were added to the points the subjects had earned during the first part of the experiment, and the person who earned the most points won $\$ 25$. Both study and test sequences were randomized separately for each subject. Both response correctness and response time (to the nearest $16 \mathrm{msec}$ ) were recorded. Six practice trials preceded the 90 test trials. At the end of the experiment, the subjects were thanked, informed of the total number of points earned, and given a written debriefing statement.

\section{Results and Discussion}

During the study phase, subjects identified more stimuli presented at the $40 \%$ level than at the $20 \%$ level $(89 \%$ and $49 \%$, respectively).

Because Experiment 3 measured both identification performance and recognition memory performance, identification data were analyzed as they were for Experiment 2 and recognition memory data were analyzed as they were for Experiment 1. In addition, performance was conditionalized on correct identification at both study and test.

Fragment identification. Table 3 shows the results of Experiment 3 in terms of proportion of items identified under each of the nine study/test conditions. Items tested with $40 \%$ fragments were, of course, better identified than items tested with $20 \%$ fragments (.94 vs. .72). Once again, there was no advantage of $20 \%$ items tested with the same fragment over $20 \%$ items tested with the complementary fragment (.75 vs. .72). Finally, there was priming inasmuch as old items were better identified than new items, although the effect measured by absolute difference scores is smaller for the $40 \%$ test condition than for the $20 \%$ test condition. Although there are procedures for dealing with ceiling effects imposed by very high baseline levels (see Snodgrass, 1989), for purposes of compatibility with Experiment 1, priming scores were computed in the usual way, as absolute difference scores. These priming scores are also shown in Table 3.

As can be seen in Table 3, the pattern of priming in Experiment 3 is very similar to that in Experiment 2 . The $40 \%$ study level produced more priming than the $20 \%$ study level ( $16 \%$ vs. $10 \%)$ and there was no sensory matching effect-the $20 \% \mathrm{~A} / 20 \% \mathrm{~A}$ priming condition produced priming identical to that of the $20 \% \mathrm{~A} / 20 \% \mathrm{~B}$ priming condition $(13 \%)$.

Because the priming effects on the $40 \%$ test were unnaturally depressed due to the very high baseline rate, we carried out a 2 (study) $\times 2$ (test) ANOVA on the priming scores for only the $20 \%$ test conditions. There was a highly significant effect of study level $\left[F(1,35)=9.52, M S_{\mathrm{e}}=\right.$ $.022, p=.004]$ but no effect of test level $[F(1,35)=1.44]$ and no interaction $[F(1,35)=2.82]$. Thus, the major results from Experiment 2 were replicated: the $40 \%$ study item produced more priming than the $20 \%$ A study item, but there was no sensory matching effect.

Next we analyzed identification scores conditionalized on correct identification at study. Table 4 shows test identification scores conditionalized on correct and incorrect identification for the two $20 \%$ study/test conditions. This pattern of results replicates that of Experiment 2 . First, items identified at study are more likely to be identified at test than are items not identified at study. The magnitude of this effect is again very large, and is shown in the "Identification advantage" row. Second, identified study items show a large matching advantage (.18), whereas unidentified study items show a more modest matching disadvantage $(-.08)$, as shown in the "Match advantage" column.

The matching advantage for identified items was highly significant $[t(35)=6.23, p<.001]$. Although the matching disadvantage for unidentified items failed to reach the traditional level of significance $[t(35)=1.67$, $p=.10]$, the numerical pattern of means replicates that of Experiment 2. An analysis combining the results of Experiments 2 and 3 demonstrates a reliable matching disadvantage for unidentified study items $[.52$ vs. .61 ; $t(62)=2.14, p<.05]$. This result suggests that the gen- 
eration of erroneous hypotheses at study harms later identification.

In summary, when overall performance was evaluated, identification performance was no better for matching fragments than it was for mismatching fragments, but when performance was conditionalized on correct identification at study, an advantage of matching over mismatching fragments emerged.

Recognition memory. Table 1 shows recognition responses (hits and false alarms) and $d^{\prime}$ values for each combination of study and test conditions in Experiment 3. The same effects observed in Experiment 1 are evident here. First, hit rates were somewhat higher for the $40 \%$ study level than for the $20 \%$ A level (.88 vs. .82). Second, hit rates were higher for the $40 \%$ test level than for the $20 \% \mathrm{~A}$ and $20 \% \mathrm{~B}$ test levels $(.92$ vs. .84 and .80$)$. Third, hit rates were higher for matching fragments than for nonmatching fragments (.86 vs. .76). False-alarm rates for new pictures were also lower for the more complete $40 \%$ level than for the less complete $20 \% \mathrm{~A}$ and $20 \%$ B levels (.07 vs. .17 and .18). Finally, the overall hit rate was higher in Experiment 3 than in Experiment 1 (.85 vs. .79).

Table 1 also shows $d^{\prime}$ values (adjusted for ceiling effects) based on pairing hit and false-alarm rates by test form. As for Experiment 1, the $d^{\prime}$ measure shows an advantage of a more complete over a less complete study fragment, except for the $20 \% \mathrm{~A}$ test level, where the matching advantage outweighed the study-level advantage and an advantage of a more complete over a less complete test fragment. Furthermore, there was a sensory matching advantage in that the matching condition $(20 \% \mathrm{~A} / 20 \% \mathrm{~A})$ was better recognized than the complementary condition $(20 \% \mathrm{~A} / 20 \% \mathrm{~B})$.

The results of a 2 (study level) $\times 3$ (test level) ANOVA on $d^{\prime}$ showed that these effects were reliable. More complete study fragments lead to better performance than do less complete study fragments $\left[F(1,35)=13.21, M S_{\mathrm{e}}=\right.$ $.155, p<.001]$, more complete test fragments lead to better performance than do less complete test fragments $\left[F(2,70)=16.20, M S_{\mathrm{e}}=.414, p<.001\right]$, and study and test levels interact because of the sensory matching effect $\left[F(2,70)=7.00, M S_{\mathrm{e}}=.166, p=.002\right]$. A planned contrast between the matching $(20 \% \mathrm{~A} / 20 \% \mathrm{~A})$ and mismatching $(20 \% \mathrm{~A} / 20 \% \mathrm{~B})$ conditions showed that the matching condition produced significantly better recognition performance ( $p=.03)$. Thus, in Experiment 3, as in Experiment 1, the unconditionalized accuracy data for recognition memory show a clear advantage for matching over mismatching fragments.

In addition, we analyzed the recognition memory hit rates conditionalized on identification at study. These conditionalized recognition scores, shown in Table 2, exhibit the same pattern of results as those from Experiment 1 . First, at test, items identified at study are more likely to be recognized as old than are items not identified at study. The magnitude of this effect is again smaller than it is for fragment identification, and is shown in the "Identification advantage" row. Second, in contrast to frag- ment identification, both identified and nonidentified study items show a matching advantage, although this time the match advantage for identified items is numerically larger than it is for unidentified items (.16 vs. .07).

A $2 \times 2$ ANOVA on hit rates for the $20 \%$ study and test conditions showed that identified items were significantly better recognized than unidentified items $[F(1,35)=17.89$, $\left.M S_{\mathrm{e}}=.036, p<.001\right]$, and matching fragments were significantly better recognized than nonmatching fragments $\left[F(1,35)=9.99, M S_{\mathrm{e}}=.048, p=.003\right]$; there was, however, no significant interaction $[F(1,35)=2.28$, $p=.14] .^{3}$

The lack of a significant interaction in Experiment 3 coupled with the same pattern of results in Experiment 1 suggests that both identified and unidentified study items show a matching advantage. This contrasts to fragment identification where only identified study items show a matching advantage. These results replicate those of Experiments 1 and 2, providing difficulties for the perceptual fluency hypothesis and supporting the episodic trace view.

Recognition memory conditionalized on test identification. An important reason for carrying out Experiment 3 was to determine whether the sensory match effect would occur even when subjects failed to identify test items. By demonstrating that sensory information could serve as a reliable basis of recognition memory in the absence of conceptual information, such a finding would provide further support for the view that sensory information was stored in episodic memory traces.

To determine whether recognition of oldness could occur in the absence of conceptual identification, it was necessary to analyze recognition memory performance conditionalized on whether or not the item was identified at test for the matching $(20 \% \mathrm{~A} / 20 \% \mathrm{~A})$ and mismatching $(20 \% \mathrm{~A} / 20 \% \mathrm{~B})$ fragment conditions. However, performance in these two test conditions was quite high (.75 and .72, respectively), so several subjects identified all items for one or both of those test conditions. To deal with missing data for the unidentified category but still have a basis on which to make statistical comparisons, 18 supersubjects were formed from the 36 subjects. These subjects were paired randomly subject to the constraint that the frequency of unidentified items across the two conditions would never be smaller than 3 . These conditionalized recognition scores are shown in Table 5. Hit rates are shown for both the $20 \% \mathrm{~A}$ and $40 \%$ study levels for the identified and not identified test items. False-alarm rates are based upon new items at the appropriate level of test $(20 \% \mathrm{~A}$ or $20 \% \mathrm{~B})$ that were either correctly identified or not identified. The $d^{\prime}$ values pair the false-alarm and hit rates by test stimulus form and test identification status.

For the $40 \%$ study level, identified items have high $d^{\prime}$ scores whereas unidentified items have $d$ ' scores that do not differ from zero (both $p \mathrm{~s}>.22$ ). For the $20 \% \mathrm{~A}$ study level, identified items also have high $d$ 's (of about the same order of magnitude as the $40 \%$ study items). More importantly, although unidentified items for the mis- 
Table 5

Recognition Memory Accuracy Conditionalized on Correct Identification at Test in Experiment 3

\begin{tabular}{ccccccc}
\hline & \multicolumn{3}{c}{ Study Level } & & \multicolumn{2}{c}{$d^{\prime}$ Values } \\
\cline { 2 - 5 } Test Level & $\begin{array}{c}20 \% \mathrm{~A} \\
(\mathrm{Hit})\end{array}$ & $\begin{array}{c}40 \% \\
(\mathrm{Hit})\end{array}$ & $\begin{array}{c}\text { New } \\
\text { (FA) }\end{array}$ & $20 \% \mathrm{~A}$ & $40 \%$ \\
\hline \multicolumn{5}{c}{ Identified at Test } \\
$20 \% \mathrm{~A}$ & 0.95 & 0.95 & 0.08 & $2.83(\mathrm{C} \& \mathrm{~S})$ & $2.85(\mathrm{C})$ \\
$20 \% \mathrm{~B}$ & 0.92 & 0.94 & 0.09 & $2.60(\mathrm{C})$ & $2.72(\mathrm{C})$ \\
& \multicolumn{7}{c}{ Not Identified at Test } \\
$20 \% \mathrm{~A}$ & 0.60 & 0.39 & 0.33 & $0.68(\mathrm{~S})$ & $0.18(\sim)$ \\
$20 \% \mathrm{~B}$ & 0.34 & 0.35 & 0.31 & $0.13(\sim)$ & $0.18(\sim)$ \\
\hline
\end{tabular}

Note-Stored memory components available at test are shown in parentheses after $d^{\prime}$ values, where $\mathrm{C}=$ conceptual, $\mathrm{S}=$ surface, and $\sim=$ none. *False alarm.

matching $(20 \% \mathrm{~B})$ test level also have $d$ 's that do not differ from zero, the matching $(20 \% \mathrm{~A})$ test level shows significant recognition memory performance for unidentified test items. The $d^{\prime}$ score of 0.68 is significantly greater than zero $[t(17)=4.25]$ and is also significantly greater than the nonmatching performance $[t(17)=2.07$, $p=.05]$. Although matching items also show an advantage over nonmatching items when they are identified ( $d^{\prime}$ scores of 2.83 vs. 2.60 ), this difference was not significant $[t(17)=1.00]$.

When an item is identified, both conceptual and sensory information from the test item is available; when an item is unidentified, only sensory information is available. Clearly, identifying the test item so that conceptual information is available produces much higher recognition memory performance than does not identifying the test item. If we assume that sensory information is available only when the test item matches the study item (in the $20 \% \mathrm{~A} / 20 \% \mathrm{~A}$ condition), we expect that both sensory and conceptual information will be available for identified matching items (indicated by the C\&S notation in Table 5) and only sensory information will be available for unidentified matching items (indicated by the S notation in Table 5). For nonmatching items, only conceptual information is available for identified test items (indicated by $\mathrm{a} C$ in Table 5) and no information is available for unidentified test items (indicated by a $\sim$ ).

This analysis predicts the pattern of results quite well. For unidentified items, only the matching test condition produced significant recognition performance; all nonmatching conditions produced zero levels of recognition, suggesting that nonmatching sensory information, in the absence of conceptual information, provides no useful information for recognition memory. The significant level of performance for the matching/unidentified condition presumably reflects the operation of the sensory information component independent of the conceptual component, and suggests that sensory information, in the absence of conceptual information, serves as a reliable basis for recognition memory. This result is consistent with the claim that sensory information is stored in episodic memory traces, serving as a basis for the sensory match effect observed by Snodgrass and Hirshman (1994) and in Experiments 1 and 3 above. Furthermore, the comparison of identified and unidentified items suggests that sensory information has its strongest influence when conceptual information is minimized (Johnston et al., 1991).

Two important effects were demonstrated in Experiments 1 through 3 . They were the presence of the sensory matching effect in recognition memory and the absence of such an effect in fragment identification. However, in all three experiments, these effects were based on using the $20 \% \mathrm{~A}$ fragment as the matching test stimulus and the $20 \% \mathrm{~B}$ fragment as the complementary test stimulus. Although performance on these two classes of fragments appeared to be equivalent for the neutral testing conditions we thought it prudent to conduct one more experiment in which the $20 \% \mathrm{~A}$ and $20 \% \mathrm{~B}$ fragments were completely counterbalanced across both study and test conditions.

\section{EXPERIMENT 4}

Experiment 4 was identical to Experiment 3 in requiring both an identification and a recognition memory response on each trial; it differed from Experiment 3 in using only $20 \%$ fragments as study and test items.

\section{Method}

Subjects and Design. The subjects were 24 students in an introductory psychology course, who volunteered as part of a course requirement. During the study phase, fragmented images at two levels $(20 \% \mathrm{~A}$ and $20 \% \mathrm{~B})$ were presented. During the test phase, half of the studied items were tested with the same (matching) fragments and half were tested with the complementary (mismatching) fragments. In addition, unstudied (new) fragments of each type were presented. The experiment thus had a 3 (study level: $20 \% \mathrm{~A}$, $20 \% \mathrm{~B}$, and new) $\times 2$ (test level: $20 \% \mathrm{~A}$ and $20 \% \mathrm{~B}$ ) design. The 90 experimental items were rotated across the six experimental conditions to produce six counterbalancing conditions. Equal numbers of subjects were assigned to each counterbalancing.

Apparatus and Procedure. Subjects were tested individually on Apple Macintosh Plus microcomputers. They were given exactly the same instructions for the study phase as subjects in Experiment 1 had been. They were also given the opportunity to win a prize of $\$ 25$ by earning points for each picture they identified during the study phase. The study sequence consisted of 64 trials; the first 4 were practice trials, and the remaining 60 were the experimental trials, of which 30 presented $20 \%$ A stimuli and 30 presented $20 \%$ B stimuli.

After the study sequence, the subjects received the same computeradministered distractor task consisting of the five simple addition problems used in Experiment 3. The final phase was the identification' recognition memory test. The instructions given to the subjects were identical to those used in Experiment 3. During the identification/ recognition memory test, the subjects were shown 90 test pictures, 60 old and 30 new. Half of the $20 \% \mathrm{~A}$ old pictures were tested with the same $(20 \% \mathrm{~A})$ fragments and half were tested with the complementary $(20 \% \mathrm{~B})$ fragments. Similarly, half of the $20 \% \mathrm{~B}$ old pictures were tested with the same $(20 \% \mathrm{~B})$ fragments and half were tested with the complementary $(20 \% \mathrm{~A})$ fragments. Half of the new pictures were from the $20 \% \mathrm{~A}$ set and half were from the $20 \% \mathrm{~B}$ set. The remainder of the procedures during the test trials were identical to those of Experiment 3. 


\section{Results and Discussion}

During the study phase, the subjects correctly identified $49 \%$ of the $20 \% \mathrm{~A}$ fragments and $50 \%$ of the $20 \% \mathrm{~B}$ fragments.

Fragment identification performance. Table 6 shows the results of Experiment 4 in terms of proportion of items identified under each of the six study/test conditions. Old items were better identified than new items, but there was no apparent advantage for the matching over the mismatching items. The priming scores (old minus baseline) are also shown in Table 6 . There is no apparent difference between versions of the fragments, nor, more importantly, is there any evidence that matching fragments are identified better than nonmatching fragments. The results of a 2 (study level) $\times 2$ (test level) ANOVA on the priming scores showed that study form, test form, and their interaction were not significant (all $p s>.15$ ). These results replicate the results of Experiments 1 and 3, and also show that the two sets of fragments appear to be equivalent.

Recognition memory performance. Table 7 shows the proportion of recognition responses (hits and false alarms) for each combination of study and test conditions in Experiment 4, along with the $d^{\prime}$ scores. Here, in contrast to identification results, there is an apparent matching advantage. Matching fragments $(20 \% \mathrm{~A} / 20 \% \mathrm{~A}$ and $20 \% \mathrm{~B} / 20 \% \mathrm{~B}$ ) produced higher performance (an average $d^{\prime}$ of 2.11) than did nonmatching fragments (an average $d^{\prime}$ of 1.73). The results of a 2 (study level) $\times 2$ (test level) ANOVA on the $d^{\prime}$ scores showed that the main effect of neither the study form nor the test form was significant (both $p \mathrm{~s}>.20$ ); however, their interaction was highly significant $[F(1,23)=27.39, p<.001]$. This interaction, of course, reflects the fact that when study and test fragments match, performance is better than when they fail to match. Furthermore, simple effects tests showed that both study forms were significantly different across the two test forms. These results replicate the results of Experiments 1 and 3 and also show that the effects are equivalent for the two versions of the $20 \%$ fragments.

Identification and recognition performance conditionalized on study identification performance. Table 8 shows identification scores and recognition memory scores (hits) conditionalized on identification at study for Experiment 4 . The pattern of results is very similar to that observed in Experiment 3 . The conditionalized data look quite similar across the two fragment versions, with one exception: recognition for unidentified study items in the recognition test is significantly lower for the $20 \% \mathrm{~A} / 20 \% \mathrm{~A}$ condition than for the $20 \% \mathrm{~B} / 20 \% \mathrm{~B}$ condi-

Table 6

Fragment Identification Performance in Experiment 4

\begin{tabular}{ccccccc}
\hline & \multicolumn{2}{c}{ Study Level (Proportion Identified) } & \multicolumn{2}{c}{ Priming } \\
\cline { 2 - 5 } \cline { 6 - 7 } Test Level & $20 \% \mathrm{~A}$ & $20 \% \mathrm{~B}$ & New & & $20 \% \mathrm{~A}$ & $20 \% \mathrm{~B}$ \\
\hline $20 \% \mathrm{~A}$ & 0.79 & 0.75 & 0.62 & & 0.18 & 0.14 \\
$20 \% \mathrm{~B}$ & 0.77 & 0.77 & 0.66 & & 0.11 & 0.11 \\
\hline
\end{tabular}

Table 7

Recognition Memory Performance in Experiment 4

\begin{tabular}{ccccccc} 
& \multicolumn{3}{c}{ Study Level } & & \multicolumn{2}{c}{$d^{\prime}$ Values } \\
\cline { 2 - 5 } Test Level & $\begin{array}{c}20 \% \mathrm{~A} \\
(\mathrm{Hit})\end{array}$ & $\begin{array}{c}20 \% \mathrm{~B} \\
(\mathrm{Hit})\end{array}$ & $\begin{array}{c}\text { New } \\
(\mathrm{FA})^{*}\end{array}$ & & $20 \% \mathrm{~A}$ & $20 \% \mathrm{~B}$ \\
\hline $20 \% \mathrm{~A}$ & 0.87 & 0.78 & 0.18 & 2.00 & 1.71 \\
$20 \% \mathrm{~B}$ & 0.79 & 0.90 & 0.16 & & 1.76 & 2.22 \\
\hline
\end{tabular}

*False alarm.

tion $[t(23)=3.30, p<.01]$. However, patterns of performance for identification and recognition in the other three conditions appear quite similar.

Accordingly, to simplify the analysis, we combined across the two fragment versions to produce the two study' test conditions of matching and mismatching. We carried out a 2 (identified at study, not identified at study) $\times 2$ (match, mismatch) within-subjects ANOVA on the identification scores. The results of this analysis indicated that identified items at study were significantly better identified at test than were unidentified items $[F(1,23)=$ $\left.307.19, M S_{\mathrm{e}}=.01, p<.001\right]$; the main effect of matching, however, was not significant $(F<1)$. There was a significant interaction $\left[F(1,23)=30.82, M S_{\mathrm{e}}=.01, p<\right.$ $.001]$. The matching-fragment condition was better than the mismatching-fragment condition for items correctly identified at study $(.99$ vs. $.87 ; p<.001)$, whereas the mismatching-fragment condition was better than the matching-fragment condition for items incorrectly identified at study (.67 vs. $.57 ; p=.02$ ). This result replicates the results of Experiments 2 and 3 and, furthermore, shows that the inhibitory effects caused by incorrectly identifying an item during study are robust.

In summary, when overall fragment-identification performance was evaluated, matching fragments did not produce better identification performance than did mismatching fragments; when performance was conditionalized on correct identification at study, an advantage of matching over mismatching fragments emerged; and when performance was conditionalized on incorrect identification at study, an advantage of mismatching over matching fragments emerged.

Next we analyzed the recognition memory hit rates for identified and unidentified study items. We carried out a similar 2 (identified at study, not identified at study) $\times$ 2 (match, mismatch) within-subjects ANOVA on the recognition scores. The results of this analysis indicated that identified items at study were significantly better recognized at test than were unidentified items $[F(1,23)=$ $\left.76.20, M S_{\mathrm{e}}=.01, p<.001\right]$ and the main effect of matching was significant $\left[F(1,23)=24.34, M S_{\mathrm{e}}=.01, p<.001\right]$; there was, however, no significant interaction $[F(1,23)=$ $\left.2.49, M S_{\mathrm{e}}=.01, p=.13\right]$.

Thus, in this experiment, as in Experiments 1 and 3, both identified and unidentified study items show a matching advantage in recognition memory, whereas, as in Experiments 2 and 3 , identified study items show a matching advantage and unidentified study items show a mismatching advantage in fragment identification. 
Table 8

\begin{tabular}{|c|c|c|c|c|c|}
\hline & \multicolumn{4}{|c|}{ Study/Test Level } & \multirow{2}{*}{$\begin{array}{l}\text { Match } \\
\text { Effect }\end{array}$} \\
\hline & $20 \% \mathrm{~A} / 20 \% \mathrm{~A}$ & $20 \% \mathrm{~A} / 20 \% \mathrm{~B}$ & $20 \% \mathrm{~B} / 20 \% \mathrm{~A}$ & $20 \% \mathrm{~B} / 20 \% \mathrm{~B}$ & \\
\hline \multicolumn{6}{|c|}{ Identification } \\
\hline Identified at study & 0.99 & 0.89 & 0.85 & 0.99 & 0.12 \\
\hline Not identified at study & 0.58 & 0.68 & 0.66 & 0.56 & -0.10 \\
\hline Identification advantage & 0.41 & 0.21 & 0.19 & 0.43 & \\
\hline \multicolumn{6}{|c|}{ Recognition } \\
\hline Identified at study & 0.99 & 0.87 & 0.85 & 0.98 & 0.12 \\
\hline Not identified at study & 0.73 & 0.72 & 0.71 & 0.84 & 0.07 \\
\hline Identification advantage & 0.26 & 0.15 & 0.14 & 0.14 & \\
\hline
\end{tabular}

Recognition memory performance conditionalized on test identification performance. Finally, we looked at recognition memory conditionalized on identification at test to see whether the reason for the recognition advantage for matching fragments was due to recognition of the unidentified fragment. Again, we collapsed across the two versions of the fragments for this analysis. Recognition memory accuracy conditionalized on identification at test is shown in Table 9. As in Experiment 3, there is an enormous advantage of test identification on hit rate in the recognition memory test. In addition, both identified and unidentified items are better recognized in the matching than in the mismatching conditions, although the differences are particularly large for the unidentified items.

The $d^{\prime}$ scores conditionalized on correct test identification are also shown in Table 9. There is a large identification advantage for both matching and mismatching fragments. In addition, there is a match advantage for both identified and unidentified test items, which is much larger for the unidentified items. Finally, recognition is near chance for the unidentified mismatching fragments $\left(d^{\prime}=\right.$ $0.13)$. This mean of 0.13 was not significantly different from zero $(t<1)$.

We carried out a 2 (identified at test, not identified at test) $\times 2$ (matching, mismatching) within-subject ANOVA on the $d^{\prime}$ scores. The results of this analysis indicated that identified items at test were significantly better recognized than unidentified items $[F(1,23)=197.60$, $\left.M S_{\mathrm{e}}=.61, p<.001\right]$, matching items were significantly better recognized than mismatching items $[F(1,23)=$ $\left.19.00, M S_{\mathrm{e}}=.43, p<.001\right]$, and there was a significant interaction $\left[F(1,23)=4.75, M S_{\mathrm{e}}=.54, p=.04\right]$. Sim-

Table 9

Recognition Memory Performance Conditionalized on Identification at Test in Experiment 4

\begin{tabular}{lllllll}
\hline & \multicolumn{3}{c}{ Study/Test Level } & & \multicolumn{2}{c}{$d^{\prime}$ Values } \\
\cline { 2 - 4 } \cline { 7 - 8 } & $\begin{array}{c}\text { Match } \\
\text { (Hit) }\end{array}$ & (Hismatch & $\begin{array}{c}\text { New } \\
\text { (FA)* }\end{array}$ & \multicolumn{2}{c}{ Match } & Mismatch \\
\hline Identified at test & 0.96 & 0.92 & 0.12 & $2.95(\mathrm{C} \& S)$ & $2.70(\mathrm{C})$ \\
Not identified at test & 0.59 & 0.30 & 0.25 & $1.04(\mathrm{~S})$ & $0.13(\sim)$ \\
\hline
\end{tabular}

Note-Stored memory components available at test are shown in parentheses after $d^{\prime}$ values, where $\mathrm{C}=$ conceptual, $\mathrm{S}=$ surface, and none. *False alarm. ple effects tests showed that matching items were significantly better recognized than nonmatching items for both test identification conditions (both $p s<.03$ ).

In summary, the results of Experiments 3 and 4 replicated the separate results of Experiments 1 and 2 in all important respects. First, there was no overall sensory match effect for fragment identification, but there was a sensory match effect when fragment identification was conditionalized on correct study identification. Second, there was an overall sensory match effect for recognition memory, occurring for both identified and unidentified study items. Finally, the sensory match effect enhanced recognition memory both when the item was identified at test (so that conceptual information was available) and when the item was not identified at test (so that conceptual information was not available). Overall, the results suggest that sensory information is stored in episodic memory traces, producing sensory match effects.

If this is so, subjects should be able to use this information deliberately to make old/new recognition memory judgments. Accordingly, the next experiment was designed to test the degree to which subjects can use surface differences alone to make their old/new decisions.

The recognition memory task used in the previous experiments might be termed concept recognition because the subject's task was to recognize whether the concept had been presented before and to ignore the surface form in which the concept was tested. Nonetheless, as we have seen, a change in surface form from study to test produced significant recognition memory decrement. In the next experiment, we used a recognition memory task that might be termed surface recognition, because the subject's task was to recognize whether the concept had been presented before in just this surface form (i.e., with just these fragments) and to reject as old the same concept tested in a different surface form.

\section{EXPERIMENT 5}

Experiment 5 differed from Experiment 1 in that the criterion for old decisions required that the concept be presented in exactly the same form at test as it had been at study. Accordingly, all concepts presented at test had been previously studied, but half of them were presented 
in the same surface form used at study and the other half were presented in a different surface form from that used at study.

\section{Method}

Subjects and Design. The subjects were 32 students in an introductory psychology course, who volunteered as part of a course requirement. The stimuli were the same 96 pictures used in the previous experiments. However, 16 items served as practice items and were not scored; the remaining 80 items served as experimental items. As in the previous recognition memory experiments, only three fragmentation levels-20\%A, $20 \% \mathrm{~B}$, and $40 \%$-were used. During the study phase, two levels-20\%A and $40 \%$-were presented, 40 items at each level. During the test phase, all three levels-$20 \% \mathrm{~A}, 20 \% \mathrm{~B}$, and $40 \%$-were presented. Half of the old items (20) were presented at the same level as studied and one quarter (10) were presented at each of the remaining two levels. The definition of "old" in this experiment was a test item presented at exactly the same level and with exactly the same fragments as at study, so this assignment of items to conditions produced equal numbers of old and new surface forms. The experiment thus had a 2 (study level: $20 \% \mathrm{~A}$ and $40 \%$ ) $\times 3$ (test level: $20 \% \mathrm{~A}, 20 \% \mathrm{~B}$, and $40 \%$ ) design. For purposes of counterbalancing, each set of old items was divided into two subsets of 10 each, thereby producing eight conditions. The 80 experimental items were rotated across these eight conditions to produce eight counterbalancing conditions. Equal numbers of subjects were assigned to each counterbalancing.

Apparatus and Procedure. The subjects were tested individually on Apple Macintosh microcomputers. They were given exactly the same instructions for the study phase as the subjects in Experiment 1 had been. They were also given the opportunity to win a prize of $\$ 25$ by earning points for each picture they identified correctly during the study phase. During the study phase, the subjects received 80 trials, 40 at the $20 \% \mathrm{~A}$ level and 40 at the $40 \%$ level. Sixteen practice trials, 8 at each study level, preceded these study trials.

After the study sequence, the subjects received a distractor task consisting of five simple addition problems. The distractor task lasted about $1 \mathrm{~min}$. The final phase was the recognition memory test. The subjects were told that in this phase of the experiment they would be tested for their memory of the pictures they had seen during study. They were also told that all the test pictures were those they had seen previously but that their task was to determine whether each picture was shown in exactly the same form as previously, in which case it should be considered old, or whether it was shown in a form different from that seen previously, in which case it should be considered new. The verbatim instructions were as follows:

Now we would like to test your memory of the pictures from the first part of the experiment. We will show you one picture at a time. Each picture will be of a concept you saw before (e.g., a "chicken"). However, sometimes the picture will be exactly the version you saw before and sometimes it will be a different version. For example, the different version might show somewhat different parts of the picture, or a more complete version of the picture, or a less complete version of the picture. Consider the exact version as "OLD" and the different version as "NEW."

During the recognition memory test, the subjects were shown 16 practice test pictures followed by 80 experimental test pictures. This larger set of practice pictures was used to ensure that the subjects were using the correct decision rule to make their recognition memory responses. These 80 experimental items had all been seen during the study phase but were presented again with either the same fragments as at study (old items) or with different fragments (new items). The numbers of items in each condition are given in Table 10. The subjects were instructed to press the bottom right-hand key (the ? key) if they thought the picture was old and to press the bottom lefthand key (the $z Z \mathrm{key}$ ) if they thought the picture was new. They were also told to respond with their first reactions and not to ago- nize over their decisions. They were told to make their decisions as quickly as possible but also to make as few errors as possible.

The words OLD and NEW were shown at the bottom of the screen to the right and left, respectively, to remind subjects which key went with which response. A trial began with a $1-\mathrm{sec}$ exposure of the warning message "get ready," followed by a $0.5-\mathrm{sec}$ blank interval. The test picture was displayed until the subject responded, at which point it was erased and information feedback in the form of the number of points won or lost was displayed for $2 \mathrm{sec}$, followed by a $0.5-\mathrm{sec}$ blank interval. Subjects won 5 points for each correct recognition response given in less than $1,000 \mathrm{msec}$, won 0 points for a correct recognition response given in more than $1,000 \mathrm{msec}$, and lost 5 points for each recognition error. Both study and test sequences were randomized separately for each subject. Both response correctness and response time (to the nearest $16 \mathrm{msec}$ ) were recorded.

At the end of the experiment, the subjects were thanked, informed of the total number of points earned, and given a written debriefing statement.

\section{Results and Discussion}

During the study phase, the subjects identified more stimuli presented at the $40 \%$ level than they did at the $20 \%$ level ( $85 \%$ and $49 \%$, respectively).

Table 10 shows proportion of recognition responses (hits and false alarms) for each study/test condition in Experiment 5. The hit rate for the $40 \% / 40 \%$ study/test level is significantly higher than the hit rate for the $20 \% \mathrm{~A}$ $20 \%$ A study/test level $[.73$ vs. $.56 ; t(31)=6.81, p<$ $.001]$. However, the false-alarm rate for the $40 \%$ test level is also higher than the false-alarm rate for the $20 \% \mathrm{~A}$ test level (.44 vs. .36). Although this difference is not statistically significant $[t(31)=1.46, p=.08]$, it does suggest that the subjects may have been biased toward calling a more complete test item old. Accordingly, the false-alarm rates corresponding to the same surface form at test (i.e., $20 \% \mathrm{~A} / 40 \%$ ) were used to correct the $40 \%$ hit rate for bias. Although there is only one false-alarm rate that corresponds strictly to the $20 \% \mathrm{~A}$ test form (that obtained in the $40 \% / 20 \% \mathrm{~A}$ study/test condition), the results of Experiment 4 had shown that $20 \% \mathrm{~A}$ and $20 \% \mathrm{~B}$ fragments were equivalent in all important respects. Accordingly, we combined the three false-alarm rates that used a $20 \%$ fragment as a test fragment to form a composite falsealarm rate for the $20 \% \mathrm{~A}$ study condition.

The resulting $d^{\prime}$ scores were significantly higher for the $40 \%$ study level than for the $20 \%$ A study level [ 0.50 vs. $0.29 ; t(31)=2.21, p=.02]$. More importantly for the purpose of the present experiment, both sets of $d^{\prime}$

Table 10

Hit Rates (Bold Face), False Alarm Rates (Italics), $d^{\prime}$ and Bias Scores $(C)$ for Experiment 5

\begin{tabular}{ccc}
\hline & \multicolumn{2}{c}{ Study Level } \\
\cline { 2 - 3 } Test Level & $40 \%$ & \multicolumn{1}{c}{$20 \% \mathrm{~A}$} \\
\hline $40 \%$ & $\mathbf{0 . 7 3}(20)$ & $0.44(10)$ \\
$20 \% \mathrm{~A}$ & $0.36(10)$ & $\mathbf{0 . 5 6}(20)$ \\
$20 \% \mathrm{~B}$ & $0.40(10)$ & $0.38(10)$ \\
$d^{\prime}$ & 0.50 & 0.29 \\
$C$ & -0.25 & 0.10 \\
\hline
\end{tabular}

Note-Numbers in parentheses represent the number of trials in each condition. 
scores were significantly greater than zero $[t \mathrm{~s}(31)=9.44$ and 4.46, respectively, $p \mathrm{~s}<.001$ ], showing that subjects are indeed capable of using surface information to make old/new recognition judgments.

Table 10 also shows the bias measure $C$, a measure of bias for signal-detection theory which is unaffected by differences in $d^{\prime}$ (see Snodgrass \& Corwin, 1988). $C$ is the location of the subject's criterion measured from the intersection of the old and new memory strength distributions in standard deviation units of the new distribution. Negative values of $C$ represent liberal criteria, and positive values of $C$ represent conservative criteria. There is a liberal "yea-saying" bias for the $40 \%$ test condition $(C=-0.25)$ and a conservative "nay-saying" bias $(C=$ 0.10 ) for the $20 \%$ test condition; the difference in biases is highly significant $[t(31)=4.08, p<.001]$. Thus, subjects have a tendency to classify a more complete picture as representing previously seen sensory information, perhaps due to the fact that they expect a previously viewed picture to appear to be more complete. Paradoxically, this is the first direct evidence we have observed that perceptual fluency may affect an aspect of recognition memory performance. Here, when there is no conceptual information on which to make an old/new judgment, subjects show a markedly increased bias to call a more complete item old.

The major conclusion from Experiment 5 is that subjects are able to make reliable old/new judgments on the basis of surface characteristics alone. This supports our view that the sensory characteristics of the study stimulus become part of the episodic record, and are thus available in a subsequent recognition memory test. It is also important to note that these results provide further difficulties for a fluency hypothesis. A fluency view might try to account for the above-chance recognition of matching fragments by hypothesizing that these fragments are perceived more fluently, providing a cue to their study form. Note, however, that this account is not sufficient. The probability of a "yes" response to a $20 \%$ A test item is significantly higher for a $20 \% \mathrm{~A}$ study item than for a $40 \%$ study item, even though the identification results (Experiments 2 and 3 ) suggest that these items are equally fluent when tested with $20 \% \mathrm{~A}$ items.

\section{GENERAL DISCUSSION}

Dual-process models of recognition memory posit a rapid familiarity judgment that is often assumed to rely on perceptual fluency. This emphasis on perceptual fluency leads to the prediction that recogition memory performance should improve when the sensory characteristics of study and test stimuli match. Snodgrass and Hirshman (1994) demonstrated this effect using picture fragments. They showed that matching the sensory characteristics of picture fragments enhanced performance in recognition memory as well as in a variety of implicit memory tasks.
The current study investigated whether the sensory matching effects reported by Snodgrass and Hirshman (1994) represented effects of perceptual fluency. Experiments 1 and 2 demonstrated that a sensory match effect occurred in recognition memory, even when it did not occur in perceptual identification. This result was replicated in Experiments 3 and 4 when test type was manipulated within subjects. Assuming that performance in perceptual identification relies on perceptual fluency, this dissociation suggests that perceptual fluency is not a sufficient explanation of sensory match effects in recognition memory.

Analyses of the results of Experiments 1 through 4, conditionalized on correct identification at study, present a more complicated picture but do not mitigate the preceding conclusion. A sensory match effect occurred for correctly identified items in perceptual identification, but a match disadvantage occurred for incorrectly identified items. On the other hand, the sensory match effect in recognition memory was positive for both identified and unidentified items. This additional dissociation is consistent with our central conclusion.

We explained the sensory match effect in recognition memory by hypothesizing that sensory information, just like conceptual and contextual information, is stored in episodic memory traces. This helps explain why the sensory match effect is positive for identified and unidentified items in recognition memory-sensory information is stored in both cases. Furthermore, it generated the predictions that (1) unidentified test items should show sensory match effects, and (2) subjects should be able to make old/new discriminations on the basis of sensory information alone. These predictions were confirmed in Experiments 3, 4, and 5.

While our focus is on recognition memory, the identification results also have important implications for conceptions of priming in perceptual identification. First, the finding that the sensory match effect occurs only for identified study items suggests that sensory match effects in perceptual identification depend on the prior association of sensory and conceptual information, an association that forms only when higher level information is retrieved in the presence of sensory information. Second, the finding that there is a match disadvantage for unidentified items suggests that the generation of erroneous hypotheses at study can impair later identification - another conceptual contribution to priming.

There are a number of other lines of evidence in the literature which question the generality of the concept of perceptual fluency, at least as a basis for correct recognition. First, we have shown in this paper that the conceptual information component in recognition memory is much more important than the sensory component, as demonstrated by the large effect of correct test identification on recognition memory performance. Second, we showed that subjects faced with a recognition memory task in which only the sensory code provides valid old/ 
new information show a strong bias toward classifying more complete items as old. Thus, subjects act as if perceptual fluency was a valid guide to oldness. Previous demonstrations of the importance of perceptual fluency in recognition memory judgments have all been based on changing subjects' criteria rather than on changing their discrimination between old and new items (e.g., Jacoby \& Whitehouse, 1989; Luo, 1993; Whittlesea, Jacoby, \& Girard, 1990). For example, Luo (1993) reported evidence that both perceptual and conceptual fluency affected subjects' tendencies to classify an item as old and showed that this effect was completely attributable to changes in response bias and not to changes in $d^{\prime}$.

In the remainder of this paper we consider alternative evidence to determine whether perceptual fluency is an important determinant of recognition memory. Mulligan and Hirshman (1995) examined this issue by investigating the time course of retrieval of two variables-sensory matching and levels of processing - hypothesized to differentially affect perceptual fluency and search, respectively. Because perceptual fluency underlies a rapid familiarity judgment, Mulligan and Hirshman expected the sensory match variable to involve a more rapid retrieval process than the levels of processing variable. Contrary to this expectation, Mulligan and Hirshman found that a speed-accuracy tradeoff function, incorporating the assumption of a single retrieval process, fit the time course of retrieval for both variables.

Given that their data did not necessitate a distinction between search and perceptual fluency, Mulligan and Hirshman (1995) noted three additional results casting doubt on the fluency hypothesis: (1) Watkins and Gibson (1988) manipulated fluency experimentally, but this did not influence recognition memory (cf. Jacoby \& Whitehouse, 1989); (2) Johnston et al. (1991) showed that correlations between perceptual fluency and recognition memory were extremely difficult to detect, occurring only following vowel-counting tasks; and (3) priming tasks indexing perceptual fluency show functional and stochastic independence from recognition memory (Hayman \& Tulving, 1989; Tulving, Schacter, \& Stark, 1982). All together, the current results and those just cited raise serious questions about whether perceptual fluency is a critical determinant of the sensory match effect in recognition memory. In contrast, the view of the sensory match effect we endorse here, that sensory information is stored in episodic memory traces, is supported by a wide range of experimental findings (Cooper \& Schacter, 1992; Cooper et al., 1992; Cooper et al., 1991; Schacter \& Cooper, 1993).

In summary, we argue in this paper that the sensory match effect in recognition memory, whereby a studied stimulus is better recognized when it is tested in the sensory form in which it was studied, occurs not because subjects experience a more rapid or more accurate perception of a matching stimulus at test, but because subjects can use stored sensory information to help in their old/ new decision. Thus, we argue that the sensory match ef- fect in recognition memory is based on the retrieval of stored information rather than on the priming of perceptual processes.

\section{REFERENCES}

ATKINSON, R. C., \& JUOLA, J. (1973). Factors influencing speed and accuracy of word recognition. In S. Kornblum (Ed.), Attention and performance $I V$ (pp. 583-612). New York: Academic Press.

ATKINSON, R. C., \& JUOLA, J. F. (1974). Search and decision processes in recognition memory. In D. H. Krantz, R. C. Atkinson, R. D. Luce, \& P. Suppes (Eds.), Contemporary developments in mathematical psychology: Vol. I. Learning, memory, and thinking (pp. 243-293). San Francisco: Freeman.

BIEDERMAN, I., \& COOPER, E. E. (1991a). Evidence for complete translational and reflectional invariance in visual object priming. Perception, 20, 585-593.

Biederman, I., \& CoOper, E. E. (1991b). Priming contour-deleted images: Evidence for intermediate representations in visual object recognition. Cognitive Psychology, 23, 393-419.

Biederman, I., \& CoOper, E. E. (1992). Size invariance in visual object priming. Journal of Experimental Psychology: Human Perception \& Performance, 18, 121-133.

Brown, H., Sharma, N. K., \& KirSner, K. (1984). The role of script and phonology in lexical representation. Quarterly Journal of Experimental Psychology, 36A, 491-505.

BRuner, J. S., \& PotTer, M. C. (1964). Interference in visual recognition. Science, 144, 424-425.

Clarke, R., \& Morton, J. (1983). Cross-modality facilitation in perceptual word recognition. Quarterly Journal of Experimental Psychology, 35A, 79-96.

COOPER, L. A., \& SCHACTER, D. L. (1992). Dissociations between structural and episodic representations of visual objects. Current Directions in Psychological Science, 1, 141-145.

Cooper, L. A., Schacter, D. L., Ballesteros, S., \& Moore, C. (1992). Priming and recognition of transformed three dimensional objects: Effects of size and reflectance. Journal of Experimental Psychology: Learning, Memory, \& Cognition, 18, 43-57.

Cooper, L. A., Schacter, D. L., \& Moore, C. (1991, November). Orientation affects both structural and episodic representations of $3-D$ objects. Paper presented at the annual meeting of the Psychonomic Society, San Francisco.

CraiK, F. I. M., \& KIRSNER, K. (1974). The effect of speaker's voice on word recognition. Quarterly Journal of Experimental Psychology, 26, 274-284.

Feustel, T. C., Shiffrin, R. M., \& Salasoo, A. (1983). Episodic and lexical contributions to the repetition effect in word identification. Journal of Experimental Psychology: General, 112, 309-346.

Hashtroudi, S., Ferguson, S., Rappold, V., \& Chrosniak, L. (1988). Data-driven and conceptually driven processes in partial word identification and recognition. Journal of Experimental Psychology: Learning, Memory, \& Cognition, 14, 749-757.

Hayman, C. A. G., \& Tulving, E. (1989). Contingent dissociation between recognition and fragment completion: The method of triangulation. Journal of Experimental Psychology: Learning, Memory, \& Cognition, 15, 228-240.

Hirshman, E., Snodgrass, J. G., Mindes, J., \& Feenan, K. (1990). Conceptual priming in fragment completion. Journal of Experimental Psychology: Learning, Memory, \& Cognition, 16, 634-647.

HumphreYs, M. S., \& BaIN, J. D. (1983). Recognition memory: A cue and information analysis. Memory \& Cognition, 11, 583-600.

JaCkson, A., \& Morton, J. (1984). Facilitation of auditory word recognition. Memory \& Cognition, 12, 568-574.

JACOBY, L. L., \& DALLAS, M. (1981). On the relationship between autobiographical memory and perceptual learning. Journal of Experimental Psychology: General, 110, 306-340.

JaCoBy, L. L., \& HaYman, C. A. G. (1987). Specific visual transfer in word identification. Journal of Experimental Psychology: Learning, Memory, \& Cognition, 13, 456-463.

JACOBY, L. L., \& WhitehouSE, K. (1989). An illusion of memory: False 
recognition influenced by unconscious perception. Journal of Experimental Psychology: General, 118, 126-135.

Johnston, W. A., HaWley, K. J., \& Elliott, J. M. G. (1991). Contribution of perceptual fluency to recognition judgments. Journal of Experimental Psychology: Learning, Memory, \& Cognition, 17, $210-223$.

KIRSNER, K. (1973). An analysis of the visual component in recognition memory for verbal stimuli. Memory \& Cognition, 1, 449-453.

KirSner, K., Milech, D., \& Standen, P. (1983). Common and modalityspecific processes in the mental lexicon. Memory \& Cognition, 11, 621-630.

KirSnER, K., \& SMith, M. C. (1974). Modality effects in word identification. Memory \& Cognition, 2, 637-640.

KoLERS, P. A. (1975). Specificity of operations in sentence recognition. Cognitive Psychology, 7, 289-306.

Kolers, P. A., \& OsTRY, D. J. (1974). Time course of loss of information regarding pattern analyzing operations. Journal of Verbal Learning \& Verbal Behavior, 13, 599-612.

Luo, C. R. (1993). Enhanced feeling of recognition: Effects of identifying and manipulating test items on recognition memory. Journal of Experimental Psychology: Learning, Memory, \& Cognition, 19, 405-413.

MANDLER, G. (1980). Recognizing: The judgment of previous occurrence. Psychological Review, 87, 252-271.

Masson, M. E. J. (1984). Memory for the surface structure of sentences: Remembering with and without awareness. Journal of Verbal Learning \& Verbal Behavior, 23, 579-592.

Mulligan, N., \& Hirshman, E. (1995). Speed-accuracy tradeoffs and the dual process model of recognition memory. Journal of Memory \& Language, 34, 1-18.

Richardson-Klavehn, A., \& Bjork, R. A. (1988). Measures of memory. Annual Review of Psychology, 36, 475-543.

ROEDIGER, H. L., III, \& BLAXTON, T. A. (1987). Effects of varying modality, surface features, and retention interval on priming in wordfragment completion. Memory \& Cognition, 15, 379-388.

Roediger, H. L., III, WELdON, M. S., STAdLeR, M. L., \& RIEGLer, G. L. (1992). Direct comparison of two implicit memory tests: Word fragment and word stem completion. Journal of Experimental Psychology: Learning, Memory, \& Cognition, 18, 1251-1269.

SCHACTER, D. L., \& COOPER, L. A. (1993). Implicit and explicit memory for novel visual objects: Structure and function. Journal of Experimental Psychology: Learning, Memory, \& Cognition, 19, 995-1009.

SNODGRASS, J. G. (1989). How many memory systems are there really?Some evidence from the picture fragment completion task. In C. Izawa (Ed.), Current issues in cognitive processes: The Tulane Floweree symposium on cognition (pp. 135-173). Hillsdale, NJ: Erlbaum.

SNODGRass, J. G., \& Corwin, J. (1988). Pragmatics of measuring recognition memory: Applications to dementia and amnesia. Journal of Experimental Psychology: General, 117, 34-50.

Snodgrass, J. G., \& FeEnan, K. (1990). Priming effects in picture fragment completion: Support for the perceptual closure hypothesis. Journal of Experimental Psychology: General, 119, 276-296.

Snodgrass, J. G., \& Hirshman, E. (1994). Dissociations among implicit and explicit memory tasks: The role of stimulus similarity. Journal of Experimental Psychology: Learning, Memory, \& Cognition, 20, 150-160.

SNodgrass, J. G., \& Vanderwart, M. (1980). A standardized set of 260 pictures: Norms for naming agreement, familiarity, and visual complexity. Journal of Experimental Psychology: Human Learning \& Memory, 6, 174-215.
SQuiRe, L. R. (1992). Memory and the hippocampus: A synthesis from findings with rats, monkeys, and humans. Psychological Review, 99 , 195-231.

SRINIVAS, K. (1993). Perceptual specificity in nonverbal priming. Journal of Experimental Psychology: Learning, Memory, \& Cognition, 19, 582-602.

Tulving, E., \& Schacter, D. (1990). Priming and human memory systems. Science, 247, 301-306.

Tulving, E., Schacter, D. L., \& Stark, H. A. (1982). Priming effects in word-fragment completion are independent of recognition memory. Journal of Experimental Psychology: Learning, Memory, \& Cognition, 8, 336-342.

WARREN, C., \& MORTON, J. (1982). The effect of priming on picture recognition. British Journal of Psychology, 73, 117-129.

WATKINS, M. J., \& GiBson, J. M. (1988). On the relation between perceptual priming and recognition memory. Journal of Experimental Psychology: Learning, Memory, \& Cognition, 14, 477-483.

WELDON, M. S., \& RoEDIGER, H. L., III (1987). Altering retrieval demands reverses the picture superiority effect. Memory \& Cognition, $15,269-280$

Whittlesea, B. W. A., Jacoby, L. L., \& GiraRD, K. (1990). Illusions of immediate memory: Evidence of an attributional basis for feelings of familiarity and perceptual quality. Journal of Memory \& Language, 29, 716-732.

WINNICK, W., \& DANIEL, S. (1970). Two kinds of response priming in tachistoscopic recognition. Journal of Experimental Psychology, 84, 74-81.

\section{NO'TES}

1. For examples of no sensory match effects, see Clarke and Morton (1983), Jacoby and Dallas (1981), Kirsner, Milech, and Standen (1983), Kirsner and Smith (1974), Roediger and Blaxton (1987), Warren and Morton (1982), and Winnick and Daniel (1970). For examples of sensory match effects, see Brown, Sharma, and Kirsner (1984), Craik and Kirsner (1974), Feustel, Shiffrin, and Salasoo (1983), Jackson and Morton (1984), Jacoby and Hayman (1987), Kirsner (1973), Kolers (1975), Kolers and Ostry (1974), Masson (1984), Roediger and Blaxton (1987), and Snodgrass and Hirshman (1994).

2. A possible criticism of this conclusion is that subjects may have thought that the fragment was something else during study, and this belief may have persisted into the test session (despite corrective feedback to the contrary), so that subjects in fact made their responses on the basis of erroneous conceptual information. In fact, of $36020 \% \mathrm{~A} / 20 \% \mathrm{~A}$ trials, the identical erroneous response was given at both study and test on only nine occasions. All statistical conclusions were identical when these trials were omitted from the analysis.

3. Because there was a trend suggesting a larger match effect for identified items in Experiment 3, we performed a $2 \times 2$ ANOVA on the data combined across Experiments 1 and 3 to provide a more powerful test of this hypothesis. This analysis demonstrated that identified items were recognized better than unidentified items $\left[F(1,71)=30.62, M S_{\mathrm{e}}=.039\right.$, $p<.001]$, and matching fragments were recognized better than nonmatching fragments $\left[F(1,71)=21.63, M S_{\mathrm{e}}=.046, p<.001\right]$. There was, however, no hint of an interaction $(F<1)$.

(Manuscript received February 14, 1995; revision accepted for publication July 19, 1995.) 